\title{
Российская Федерация и ДОВСЕ: \\ самооборона без применения \\ вооруженной силы
}

\section{Шимановская Д.О.*}

Весна-лето текущего года ознаменовались крупными изменениями в отношениях Россия - НАТО в области международной безопасности. Речь идет прежде всего о кризисе Договора об обычных вооруженных силах в Европе (ДОВСЕ): Российская Федерация приостановила действие этого Договора (мораторий вступил в силу 12 декабря 2007 г.). Это комплексная проблема, в которой тесно переплетаются политическая и правовая сторона, одну нельзя рассматривать в отрыве от другой.

В 1990 г. в Париже два равносильных блока - государства Варшавского договора и НАТО - подписали Договор об обычных вооруженных силах в Европе. Основная цель данного Договора - снизить количество вооруженных сил в Европе до уровня, не позволяющего ни одному из блоков провести успешную наступательную операцию. Договором вводились квоты на количество единиц боевых танков, боевых бронированных машин, артиллерии, боевых самолетов и боевых вертолетов. Эти квоты были разделены поровну между НАТО и участниками Варшавского договора, так что ни одна из сторон не имела перевеса. Район применения ДОВСЕ - сухопутная территория от Атлантического океана до Уральских гор, а также вся территория к западу от реки Урал и Каспийского моря и Турция - до точки пересечения турецкой границы с 39-й параллелью. Однако после объединения Германии, распада СССР и разделения Чехословакии равновесие было сильно нарушено и Договор перестал соответствовать реальному положению вещей. Поэтому в 1999 г. в Стамбуле было заключено Соглашение об адаптации Договора об обычных вооруженных силах в Европе (так называемый «адаптированный ДОВСЕ»). Данное Соглашение заменяет зональный принцип, заложенный в основу первоначального Договора, на национальный и территориальный. Адаптированный ДОВСЕ также существенно отличается от первоначального составом участников: новый Договор подписали государства-партнеры России по СНГ: Азербайджан, Армения, Беларусь, Грузия, Молдова, Украина.

* Шимановская Дарья Олеговна - аспирант Дипломатической академии МИД России. 
Адаптированная система ДОВСЕ нацелена на обеспечение интересов безопасности каждого в отдельности государства-участника, независимо от их принадлежности к региональным организациям или военно-политическим союзам. Однако в связи с тем, что адаптированный ДОВСЕ так и не был ратифицирован странами - участницами НАТО, действует Договор 1990 г., подписанный Советским Союзом. Таким образом, в порядке правопреемства обязательства по ДОВСЕ несет только Российская Федерация, ратифицировавшая оба договора. Свой отказ от ратификации адаптированного ДОВСЕ наши партнеры по Договору мотивируют неисполнением российской стороной Стамбульских договоренностей о выводе российских войск из Грузии и Приднестровья, ссылаясь на пункт 42 Заявления по итогам встречи НАТО на высшем уровне в Риге в 2006 г.: «Выполнение оставшихся стамбульских обязательств по Республике Грузия и Республике Молдова создаст условия, позволяющие Союзникам и другим государствам - участникам Договора продвинуться вперед на пути ратификации адаптированного ДОВСЕ. Мы приветствуем важное соглашение о выводе российских войск, подписанное Россией и Грузией 31 марта 2006 г., и прогресс, достигнутый с тех пор. Мы с сожалением отмечаем продолжающееся отсутствие прогресса в выводе российских вооруженных сил из Республики Молдова, и мы призываем Россию возобновить и завершить вывод войск как можно скорее». Для России такая постановка вопроса является неприемлемой, так как не существует юридической связи между ратификацией странами НАТО Соглашения об адаптации ДОВСЕ и выводом российских войск с территории Грузии и Молдовы, и об этом неоднократно говорил Президент России. Объяснить эту ситуацию можно только желанием НАТО оказать давление на Россию, добиться таким образом приближения реализации своих геополитических задач. Что же касается непосредственно вопроса о выводе российских войск с указанных территорий, то высшие должностные лица России неоднократно озвучивали нашу позицию по этому вопросу: российская сторона соблюдает график вывода войск из Грузии; в Приднестровье же российский миротворческий контингент занимается эвакуацией оставшихся в регионе арсеналов 40-й армии и охраной больших военных складов, которые нельзя бросить на произвол судьбы ${ }^{1}$.

Этот актуальный вопрос, относящийся одновременно к международным отношениям и к национальной безопасности Российской

${ }^{1}$ Российская газета, 27 апреля 2007 г. № 90. С. 5. 
Федерации, президент России В.В. Путин затронул в своем последнем Послании Федеральному Собранию². В частности, президент заявил, что «...наши партнеры в данном случае ведут себя как минимум некорректно, добиваясь односторонних преимуществ. Не ратифицируя под надуманным предлогом ДОВСЕ, они используют сложившуюся ситуацию для наращивания возле наших границ системы военных баз».

В связи с обострением вопроса о ДОВСЕ в Вене с 11 по 15 июня 2007 г. прошла внеочередная конференция государств - участников ДОВСЕ, созванная по требованию Российской Федерации. На этой конференции российская сторона обозначила следующие условия, необходимые для восстановления жизнеспособности режима ДОВСЕ:

1) возвращение Латвии, Литвы и Эстонии в договорное поле. Дело в том, что с вступлением в НАТО новых членов, не являющихся участниками ДОВСЕ (прибалтийские государства, Словакия), блок получил возможность размещать на свободных от ограничений по ДОВСЕ территориях любое вооружение. Необходимо учитывать также, что некоторые новые члены НАТО - это бывшие союзники СССР по Варшавскому договору (Болгария, Венгрия, Польша, Румыния и Чехия). Таким образом, паритет, заложенный в Договор об обычных вооруженных силах в Европе, окончательно нарушен;

2) понижение суммы разрешенных уровней и наличия ограничиваемой Договором военной техники (ОДВТ) стран НАТО в целях компенсации потенциала, приобретенного альянсом в результате его расширения;

3) принятие политического решения об отмене фланговых ограничений для территории России, которые представляют собой обязательства России иметь на южных и западных границах определенное количество войск, боевой техники и вооружений. В связи с вооруженным конфликтом в Чечне квота России во фланговых зонах была увеличена. При этом необходимо отметить, что Российская Федерация, будучи единственной страной, имеющей эти фланговые ограничения, тем не менее согласовывала свои действия с партнерами даже при серьезном обострении ситуации внутри страны;

4) разработка общего понимания термина «существенные боевые силы» и проявление соответствующей сдержанности в период до его согласования;

2 Опубликовано в Российской газете. 27 апреля 2007 г. № 90. 
5) вступление в силу или по крайней мере начало временного применения Соглашения об адаптации не позднее 1 июля 2008 г.; разработка условий присоединения к ДОВСЕ новых участников и дальнейшая модернизация.

К сожалению, конференцию в Вене нельзя назвать успешной. Проблемы, поставленные руководством нашей страны, не нашли понимания у членов НАТО. Сторонам не удалось даже договориться о принятии заключительного документа конференции в связи с расхождениями по двум принципиальным вопросам, что отражено в Заявлении делегации Италии, которое она сделала от имени участвующих в конференции стран - членов НАТО:

1) НАТО настаивает на включении в текст заключительного документа «своей принципиальной позиции», отраженной в пункте 42 Декларации рижской встречи в верхах НАТО 2006 г. В связи с этим не предвидится положительной динамики в процессе ратификации Соглашения об адаптации ДОВСЕ участниками НАТО. Предложение Российской Федерации, внесенное ею на Внеочередной конференции в Вене, заключалось в следующем: государства-участники, которые еще не ратифицировали Соглашение об адаптации, должны не позднее 1 октября 2007 г. начать национальные процедуры ратификации, имея целью сдачу последнего документа о ратификации Депозитарию ДОВCЕ не позднее 15 июня 2008 г. В случае, если к 25 июня 2008 г. Соглашение об адаптации не вступит в силу, государства-участники примут решение о его временном применении (за исключением положений, относящихся к территориальным предельным подуровням и к дополнительным платным инспекциям) с 1 июля 2008 г. до официального вступления в силу. С 1 июля 2008 г. государства-участники начнут в рамках Совместной консультативной группы консультации об условиях присоединения новых государств к адаптированному ДОВСЕ и переговоры о дальнейшей модернизации адаптированного Договора с учетом изменения военно-политической ситуации в Европе;

2) вторая неразрешимая на сегодняшний день проблема - режим фланговых ограничений, «который все союзники по НАТО считают краеугольным камнем европейской безопасности и стабильности».

В связи с таким исходом переговоров Российская Федерация предприняла следующий шаг: 14 июня 2007 г. президент В.В. Путин подписал Указ «О приостановлении Российской Федерацией действия Договора об обычных вооруженных силах в Европе и связанных с ним 
международных договоров», согласно которому действие ДОВСЕ и связанных с ним международных договоров ${ }^{3}$ приостанавливается через 150 дней после получения депозитариями указанных договоров уведомлений об их приостановлении. 3 декабря 2007 г. вступил в силу Федеральный закон Российской Федерации от 29 ноября 2007 г. № 276-Ф3 «О приостановлении Российской Федерацией действия Договора об обычных вооруженных силах в Европе», на основании которого действие Договора было приостановлено для Российской Федерации в ночь с 12 на 13 декабря 2007 г. Указ президента сопровождается справкой, в которой подчеркивается, что действие ДОВСЕ приостанавливается в соответствии с международным правом, а сам Указ содержит ссылку на пункт 4 статьи 37 Федерального закона от 15 июля 1995 г. № 101-Ф3 «О международных договорах Российской Федерации» ${ }^{4}$.

С точки зрения российского права вопрос представляется ясным, вызывает интерес ссылка на международное право. Какие нормы международного права позволяют Российской Федерации принять решение о приостановлении действия ДОВСЕ? Обратимся прежде всего к Венской конвенции о праве международных договоров 1969 г. Статья57 Конвенции предусматривает возможность приостановления действия договора в отношении всех участников или в отношении отдельного участника в соответствии с положениями договора или с согласия всех участников по консультации с прочими договаривающимися государствами 5 . Договор об обычных вооруженных силах в Европе не предусматривает возможности приостановления действия Договора. Однако

3 Соглашения о максимальных уровнях для наличия обычных вооружений и техники Народной Республики Болгарии, Венгерской Республики, Республики Польша, Румынии, Союза Советских Социалистических Республик и Чешской и Словацкой Федеративной Республики в связи с Договором об обычных вооруженных силах в Европе, подписанного в г. Будапеште 3 ноября 1990 г., и Документа, согласованного государствами - участниками Договора об обычных вооруженных силах в Европе от 19 ноября 1990 г., являющегося приложением к Итоговому документу первой конференции по рассмотрению действия Договора об обычных вооруженных силах в Европе и Итогового акта переговоров о численности личного состава (г. Вена, 15-31 мая 1996 г.).

4 «Действие международного договора Российской Федерации, решение о согласии на обязательность которого для Российской Федерации принималось в форме федерального закона, может быть приостановлено Президентом Российской Федерации в случаях, требующих принятия безотлагательных мер, с обязательным незамедлительным информированием Совета Федерации и Государственной Думы и внесением в Государственную Думу проекта соответствующего федерального закона».

5 Международное право: сборник документов. М., 2000. С. 94. 
статья XIX Договора устанавливает право участников на односторонний выход из Договора: «Каждое государство-участник в порядке осуществления своего национального суверенитета имеет право выйти из настоящего Договора, если оно решит, что относящиеся к содержанию настоящего Договора исключительные обстоятельства поставили под угрозу его высшие интересы. Государство-участник, намеревающееся выйти из Договора, уведомляет депозитария и все другие государства-участники о своем решении поступить таким образом. Такое уведомление направляется по меньшей мере за 150 дней до предполагаемого выхода из настоящего Договора. Оно включает заявление об исключительных обстоятельствах, которые это государство-участник рассматривает как поставившие под угрозу его высшие интересы». И хотя Указ президента от 14 июня 2007 г. не содержит прямой ссылки на эту статью Договора, есть основания полагать, что он опирается именно на эту норму международного права, о чем свидетельствует установленный в Указе срок в 150 дней, который соответствует сроку, установленному Договором. При этом причина, по которой Указ не ссылается напрямую на данную статью Договора, ясна: Указом действие Договора приостанавливается, а не прекращается, тогда как в статье XIX Договора речь идет именно о выходе из него. Эта статья будет применена в случае, если в результате отсутствия изменений в позициях сторон встанет вопрос о выходе Российской Федерации из ДОВСЕ. О такой возможности неоднократно предупреждало российское руководство ${ }^{6}$. Итак, ДОВСЕ не предусматривает возможности приостановления действия Договора одним из его участников. Что касается второй возможности по договоренности всех участников договора, то в случае с ДОВСЕ основная проблема и заключается в отсутствии согласия между участниками Договора относительно его дальнейшей судьбы.

И хотя понятно, что решение о приостановлении ДОВСЕ промежуточное, политическое, имеющее своей целью подтолкнуть партнеров по Договору к его ратификации и добросовестному исполнению, необходимо все-таки подвести под него убедительную правовую базу. Для этого надо взглянуть на проблему шире.

6 Например, в своем выступлении по итогам министерского заседания Совета Россия - НАТО 26 апреля 2007 г. министр иностранных дел России С.В. Лавров заявил, в частности: «...А если разговор не приведет к радикальным изменениям и наши партнеры по-прежнему будут отказываться его ратифицировать, то назреет вопрос о выходе из ДОВСЕ». 
Совершенно очевидно, что политика НАТО в последние годы носит не просто конфронтационный, но наступательный характер по отношению к России. Вашингтонский договор (так называемый «Устав НАТО») создавал эту организацию в качестве оборонительного альянса от возможной агрессии со стороны Советского Союза. С окончанием холодной войны, и тем более с распадом Советского Союза, исчезла основная цель существования этой организации - отражение нападения со стороны СССР. Однако страны, входящие в НАТО, не спешили отказаться от участия в альянсе и единодушно высказались за целесообразность сохранения НАТО. В 1991 г. в Риме была принята Новая стратегическая концепция НАТО, а затем еще одна в Вашингтоне в том же году. Годом ранее государства Варшавского договора и НАТО подписали Договор об обычных вооруженных силах в Европе (ДОВСЕ). В этих документах Североатлантический альянс закрепил свой отказ от концепции тотальной войны на восточном направлении, перенеся акцент с коллективной обороны на урегулирование кризисных ситуаций.

Однако несмотря на задекларированные мирные цели этой организации, НАТО ведет активную политику расширения своего военного присутствия в Восточной Европе. Начало процессу расширения НАТО на восток было положено с принятием программы «Партнерство ради мира» (ПРМ) в 1994 г., адресованной всем участникам ОБСЕ, не являвшимися членами НАТО. Индивидуальные программы в рамках ПРМ с НАТО заключили государства Центральной и Восточной Европы, СНГ (в том числе и Россия), нейтральные страны Западной Европы. В то же время был запущен процесс принятия новых членов в состав альянса. Решение о начале расширения НАТО было принято Советом этой организации в 1996 г. Первыми в расширяющийся альянс вошли Венгрия, Польша и Чехия. При этом расширение проходило под лозунгом «распространения демократических ценностей», так как кандидатам на вступление в НАТО был поставлен, помимо прочего, ряд политических условий, таких как: завершение демократических реформ, обеспечение прав национальных меньшинств, установление гражданского контроля над вооруженными силами. Таким образом было предложено некое нравственное оправдание по сути агрессивного, а значит, противоправного процесса расширения Североатлантического альянса. Второй этап расширения НАТО пришелся на 2004 г., когда в состав этой организации вошли Болгария, Латвия, Литва, Румыния, 
Словакия, Словения, Эстония. При этом требования к кандидатам относительно уровня демократии в этих странах были сильно снижены. Было решено, что альянс сам будет способствовать продвижению демократических реформ в этих странах после их вступления в НАТО. Очевидно, уровень демократизации вновь принятых участников все же не является существенным фактором для лидеров альянса. Их привлекает другое - географическое и стратегическое расположение этих стран: расширяясь в восточном направлении, альянс скоро обеспечит себе военное присутствие по всему периметру российских границ. Такие опасения подтверждаются, помимо прочего, высказываниями первых лиц США. Так, в интервью французской газете «Фигаро» в 2001 г. К. Райс заявила: «Я не устала повторять, что сегодня главная угроза, нависшая над миром, исходит от загнанной в угол России, в том смысле, что часть ее ядерного потенциала рискует попасть в плохие руки, а именно - «государствам-изгоям» или террористическим организациям. Я также знаю, что в определенный момент ее (России) интересы войдут в противоречие с нашими» ${ }^{7}$.

Еще одно важнейшее изменение касается выхода альянса за пределы определенной в его Уставе зоны ответственности ${ }^{8}$. Первым примером применения НАТО вооруженной силы за пределами территорий стран-участников стало вооруженное вмешательство альянса в конфликт вокруг Косово. Как неоднократно говорилось, эта операция, громко названная ее участниками «Решительная сила», была проведена в нарушение огромного количества норм международного права: это и применение силы против суверенного государства, и вмешательство во внутренние дела государства, и, наконец, нарушение как минимум двух положений своего собственного Устава.

В 2003 г. НАТО предприняло энергичную попытку распространить свое влияние уже за пределы Европы, взявшись за обеспечение стабильности в Афганистане в рамках Международных сил $\mathrm{OOH}$, созданных для содействия безопасности в этой стране.

Следующим полем приложения энергии альянса стал Ирак. И хотя позиции стран - участниц НАТО по этому вопросу во многом разошлись, не стоит переоценивать тенденцию к внутреннему расколу в организации. В противовес консервативной и миролюбивой позиции таких стран, как Франция и Бельгия, новые члены альянса, а также

7 Российская газета. 4 мая 2007 г. С. 10.

8 Эта зона определена в ст. 6 Вашингтонского договора. 
Великобритания демонстрируют активную поддержку агрессивной политики Соединенных Штатов.

И хотя, по мнению координатора Комитета по Восточной Европе и России в НАТО, «Североатлантический договор... не накладывает ограничений на сферу действия НАТО... В пределах... зоны, которая включает в себя территории стран - участниц НАТО, у государствчленов имеется обязательство действовать. За ее пределами участники НАТО оставляют за собой скорее право действовать, нежели обязанность действовать» ${ }^{9}$, юристу сложно согласиться с таким надуманным аргументом. Вашингтонский (или Североатлантический) договор устанавливает не только район действия членов НАТО в исполнение ими данного Договора, но и цели этих действий - коллективная самооборона. А в перечисленных выше случаях блок, выйдя за пределы своей территории, вышел одновременно и за пределы своей компетенции: применение вооруженной силы альянсом не имеет никакого отношения к самообороне, а носит, наоборот, наступательный, агрессивный характер и преследует противоправные цели (это и «гуманитарная интервенция», и принудительная смена политического режима в суверенном государстве).

Итак, сегодня мы имеем дело с абсолютно новой и по составу, и по целеполаганию, организацией, возникшей на месте оборонительного альянса. Обновленное НАТО стремится к расширению сферы своего влияния в мире, добиваясь этого путем установления военного контроля во всех стратегических точках земного шара. Самый большой интерес у энергичных лидеров альянса вызывает Ближний Восток и, разумеется, Россия. Можно ли рассматривать такую политику как дружественную? Как относиться к созданию альянсом системы военных баз по периметру границы Российской Федерации и к планам Соединенных Штатов по размещению системы противоракетной обороны в Европе? Эти планы США вызывают у руководства нашей страны обоснованное беспокойство. Приведем для примера заявление Начальника Генерального штаба Вооруженных Сил РФ Ю. Балуевского: «Иран сегодня и Северная Корея в прошлом - это лишь маскировка реального предназначения системы: изменение стратегического баланса в свою пользу за счет создания условий для более эффектив-

\footnotetext{
9 Штраус А. Мифы и мистификации о НАТО и международном праве // Московский журнал международного права. 2002. № 2. С. 86.
} 
ного применения стратегических ядерных сил. Основная цель района ПРО в Европе - это Россия» ${ }^{10}$.

Как указывалось выше, Устав ООН запрещает не только применение силы, но и угрозу ее применения. Возникает вопрос: какие действия государств можно рассматривать как угрозу применения силы? Безусловно, таковыми являются заявления высших должностных лиц одного государства о возможности применения им вооруженной силы против другого государства. По нашему мнению, угрозой применения силы следует считать также действия государства по подготовке возможного вооруженного нападения на другое государство: направление боеголовок ракет в сторону другого государства, наращивание возле его границ своего военного присутствия, развертывание там систем военных баз и др. Очевидно, что в таких условиях применение вооруженной силы для самообороны при отсутствии вооруженного нападения со стороны угрожающего государства представляло бы собой противоправное действие, акт так называемой «превентивной самообороны» ${ }^{11}$ (автор придерживается узкого толкования ст. 51 Устава ООН: применение вооруженной силы в порядке самообороны возможно только в ответ на вооруженное нападение).

Представляется, однако, что выход из сложившейся ситуации можно найти, применив принцип соразмерности. Да, использование вооруженной силы в условиях отсутствия вооруженного нападения является грубым нарушением международного права. Но государство, оказавшееся под угрозой, может использовать другие средства для защиты от возможного нападения - прибегнуть к самообороне без использования вооруженной силь (курсив мой. - Д.Ш.). По нашему мнению, примером такого вида самообороны можно считать предложение Президента РФ В.В. Путина объявить мораторий на исполнение Россией Договора об обычных вооруженных силах в Европе. Такие действия всего лишь восстанавливают status quo, уравновешивают позиции сторон. При этом следует вспомнить аргументацию Соединенными Штатами их одностороннего выхода из Договора по ПРО, который с 1972 г. представлял собой основу стратегической стабильности в мире: в 2000 г. Соединенные Штаты мотивировали свой отказ

10 Ю. Балуевский. Про ПРО // Российская газета. 4 мая 2007 г. С. 10.

${ }^{11}$ Истории известен подобный случай: в 1981 г. Израиль атаковал ядерные установки в Ираке, потому что их боеголовки были направлены на Израиль, мотивируя свои действия правом на самооборону в ответ на непосредственную угрозу со стороны Ирака. 
от исполнения Договора необходимостью обороны национальной территории от ударов ракет «стран-изгоев».

Действительно, решение Российской Федерации о приостановлении действия ДОВСЕ продиктовано интересами национальной безопасности: нельзя бездействовать, когда складывается ситуация, наносящая ущерб обороноспособности страны и представляющая угрозу для ее территориальной неприкосновенности и политической независимости. Любопытно, что такая ситуация, как уже частично отмечалось выше, вполне укладывается в рамки концепции о превентивной самообороне, развиваемой прежде всего Соединенными Штатами Америки. Так, в Стратегии национальной безопасности США 2006 г. говорится: «It is an enduring American principle that this duty obligates the government to anticipate and counter threats, using all elements of national power, before the threats can do grave damage. The greater the threat, the greater is the risk of inaction - and the more compelling the case for taking anticipatory action to defend ourselves, even if uncertainty remains as to the time and place of the enemy's attack» ${ }^{12}$. Это описание полностью применимо к ситуации расширения НАТО на Восток и размещения ПРО в Европе в условиях отказа стран Альянса от ратификации Соглашения об адаптации ДОВСЕ. И хотя у России в этой связи не возникает права на применение вооруженной силы в соответствии с Уставом $\mathrm{OOH}$, Российская Федерация может прибегнуть к адекватным и соразмерным мерам, не связанным с применением вооруженной силы, чтобы предотвратить худшее - утрату территориальной целостности и суверенитета в результате агрессии, которую по причинам добросовестного исполнения Договора об обычных вооруженных силах в Европе мы уже не сможем предотвратить.

Безусловно, в интересах как Российской Федерации, так и НАТО в кратчайшие сроки урегулировать возникшие разногласия и начать добросовестно придерживаться режима ДОВСЕ, что прежде всего требует ратификации Соглашения об адаптации ДОВСЕ всеми его участниками. В пылу политической борьбы нельзя забывать о принципиальном значении самого Договора, который «нейтрализует угрозу создания

12 «... США долгое время придерживаются принципа, заключающегося в том, что правительство должно предвидеть угрозы и противостоять им, используя все возможности федеральной власти, до того, как эти угрозы смогут вылиться в значительный ущерб. Чем серьезнее угроза, тем большую опасность представляет бездействие и тем больше оснований для совершения упреждающих действий для самозащиты, даже если время и место ожидаемого нападения врага остается неизвестным» (перевод мой. - Д.Ш.). 


\section{The Russian Federation and the CFE Treaty: Self-defense without Use of Force (Summary)}

\section{Daria O. Shimanovskaya*}

This article is devoted to the unfortunate situation around the Treaty on Conventional Forces in Europe (the CFE Treaty). This Treaty adopted by two blocks (NATO and Warsaw Pact countries) in 1990 was assigned to decrease the quantity of military forces in Europe so that neither party would have an advantage over the other.

But the international conditions have changed dramatically: the USSR collapsed and the NATO recruited new members, including those who used to be parties to the Warsaw Pact. The parity was consequently broken. So in 1999 in Istanbul there was signed the Agreement on Adaptation of the CFE Treaty (the so called "adopted CFE"). The RF and a few CIS countries have ratified this Agreement, in contrast to the NATO countries, who refuse ratification until Russia withdraws its troops from Georgia and Moldova.

So RF convened an emergency conference of the countries-parties to the CFE Treaty. After the participants failed to reach an agreement Russian president took the decision to suspend the Treaty until the NATO countries ratify the Agreement on adaptation (the moratorium entered into force on December, 12, 2007). This decision can not be based on provisions of the Treaty itself as it provides only for denunciation (not suspension). But Russian government can refer to the right of self-defense without use of force, because this situation (taking into account the NATO expansion and the plans to station the ABM in Europe) threatens territorial integrity and sovereignty of the Russian Federation.

13 Справка к Указу «О приостановлении Российской Федерацией действия Договора об обычных вооруженных силах в Европе и связанных с ним международных договоров».

* Daria O. Shimanovskaya - post-graduate student of the Diplomatic Academy, MFA Russia. 